\title{
Factors Associated with Overweight and Central Obesity in Adults at Gilgel Gibe Field Research Center, Southwest Ethiopia: A Secondary Analysis of Data
}

\author{
Girma Yazew $^{1} \quad$ Abdulkerim Abate $^{2} \quad$ Fessahaye Alemseged $^{3} \quad$ Tsegaye Tewelde $^{4}$ \\ 1,2,3,4 Department of Epidemiology, College of Public Health and Medical Sciences, Jimma University, Jimma, \\ Ethiopia.
}

\begin{abstract}
Introduction: Overweight and obesity increase the risk of premature death and cause serious chronic conditions that reduce the overall quality of life and decrease productivity. Studies on factors associated with overweight and central obesity are lacking.Therefore; this study was undertaken to assess factors associated with overweight and central obesity in adults at Gilgel Gibe Field Research Center. Methods: Source of data was from a community based cross-sectional study conducted from September 2008 to January 2009 using WHO stepwise of stratified random sampling method. All study participants of age 15 to 64 years, who had anthropometric measurements were included in this study. Data were entered into the computer using EPI-Data version 3.1 and analyzed by SPSS Windows version 16.0 software. Binary logistic regression analysis was carried out and p-value less than 0.05 was considered as statistically significant association. Results: Ninety six percent of study participants were included in the study. Respondents of age, 55-64 years and female sex were more likely to develop overweight and central obesity $[(\mathrm{AOR}=8.3 ; 95 \% \mathrm{CI}, 2.080-33.20),(\mathrm{AOR}=3 ; 95 \% \mathrm{CI}, 1.37-6.98)]$ and $[(\mathrm{AOR}=2.5 ; 95 \% \mathrm{CI}, 1.71-3.670)$, $(\mathrm{AOR}=12 ; 95 \% \mathrm{CI}, 4.27-20.46)]$ respectively. Higher educational status, urban residence, employee and merchant were more likely to be overweight $[(\mathrm{AOR}=6.2 ; 95 \% \mathrm{CI}, 2.12-17.95),(\mathrm{AOR}=4.2 ; 95 \% \mathrm{CI}, 2.170-8.180),(\mathrm{AOR}=$ $5.9 ; 95 \% \mathrm{CI}, 1.66-21.03)$ and $(\mathrm{AOR}=5.4 ; 95 \% \mathrm{CI}, 1.65-14.8)]$ respectively. But higher educational status and chewing chat were less likely to became central obese [(AOR=0.36; $95 \% \mathrm{CI}, 0.210-0.736)$ and $(\mathrm{AOR}=0.44$; 95\%CI, 0.359-0.548)] respectively. Conclusion: Older age, female sex and higher educational status were independently associated with overweight and central obesity. Current smoker and chewing chat for central obesity and merchant, employee and urban residence for overweight were independently associated. Woreda Health Offices should encourage health facilities to promote prevention and control of overweight and central obesity among females and urban residents.
\end{abstract}

Keywords: Overweight, Central obesity, Gilgel Gibe Field Research Center.

DOI: $10.7176 / \mathrm{JHMN} / 63-02$

Publication date:June $30^{\text {th }} 2019$

\section{INTRODUCTION}

Worldwide, $35 \%$ of adults aged 20 years and older were overweight (BMI $\left.\geq 25 \mathrm{~kg} / \mathrm{m}^{2}\right)(34 \%$ men and $35 \%$ of women) in 2008. An estimated 297 million women and 205 million men over the age of 20 were obese in 2008. Overweight and obesity are increasing worldwide due to changes in diet and increasing physical inactivity $[1,2]$. Different studies done on overweight and obesity revealed that several factors associated with overweight and central obesity. But there were a few studies done on the prevalence of overweight and obesity in Ethiopia. For example, prevalence of overweight and central obesity were high in Gilgel Gibe Field Research Center area [3]. However, studies done on factors associated with overweight and central obesity are lacking. Therefore, this study helps to identify factors associated with overweight and central obesity in the study area. An evidence produced from this finding will also contribute for the health policy makers, researchers and health managers to apply lesson learned to ensure a successful strategy to fight overweight and central obesity, in addition, it helps as information for further analytical study.

Conceptual framework which was developed after reviewing different articles and adapted from study conducted by Méjean C. et al in 2007 [4] consists of independent variables (socio-demographic, behavioral and biological factors) associated with the dependent variables (overweight and central obesity) as shown below (Figure 1). 


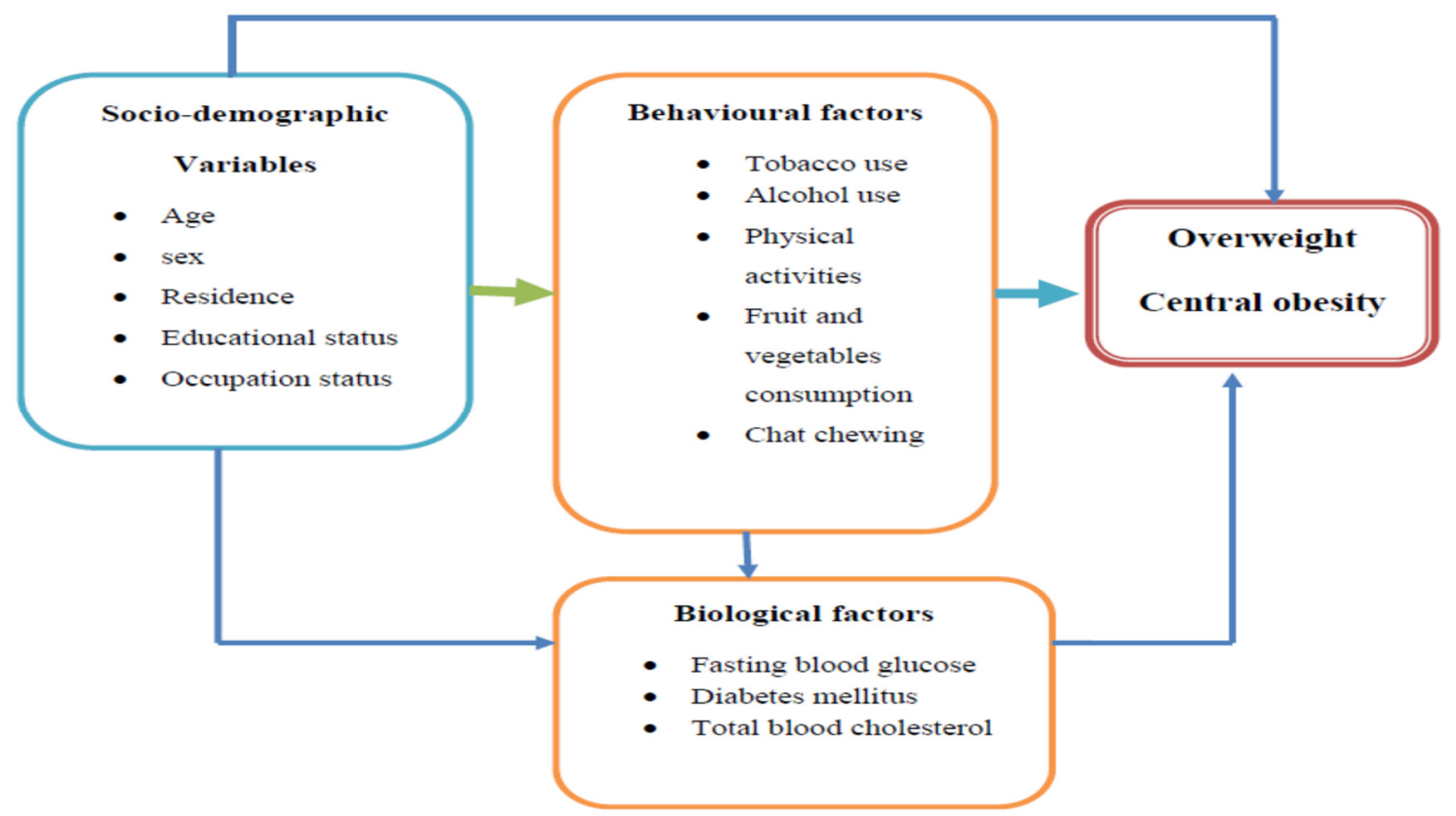

Figure 1: Conceptual framework for overweight and central obesity

\section{METHODS AND MATERIALS}

Source of data for this study was from the study done at Gilgel Gibe Field Research Center (GGFRC) area of Jimma University (JU) from late September 2008 to end of January 2009. The study was conducted for the determination of magnitude of chronic non communicable diseases (CNCDs), risk factors of CNCDs, immunological and hematological value determination. cross sectional study was used to assess factors associated with overweight and central obesity in adults at GGFRC. The GGFRC is a center that serves as health and demographic surveillance system for Jimma University and comprises of eight rural and two urban kebeles (the lowest administrative unit). The study area comprised about 11,000 households with a total population of 50,000 in the center and out of the total population; age group of 15 to 64 years comprised about $49 \%$. The population was stratified by age (15-24 years, 25-34 years, 35-44 years, 45-54 years and 55-64 years), sex and residential area (urban and rural) and such stratification was considered in the sample size calculation. For interviews and physical measurement 250 individuals from each age and sex stratum were taken giving a sample size of 2500 . However, due to further stratification by residential area, the sample size was doubled to 5,000 and taking $10 \%$ non-response rate, the total sample size became 5,500 [3]. In this study, two thousand five hundred and thirty seven (2537) study participants, who had anthropometric measurements were included.

Stratified random sampling technique was used and sample was allocated to each age, sex and residential area stratum proportional to its size. The list of the population and households of ten kebeles of 2008 updated census was used as the sampling frame. Taking $25 \%$ urban and $75 \%$ rural population distribution in the center, the total sample distributed proportionally in which 1376 from urban and 4124 from rural. Then, the sample was distributed to each kebele proportional to their population size. Using sex and age stratified sampling frame obtained from the census list, individuals were selected by simple random sampling [3]. Here is schematic presentation of sampling procedure (Figure 2) 


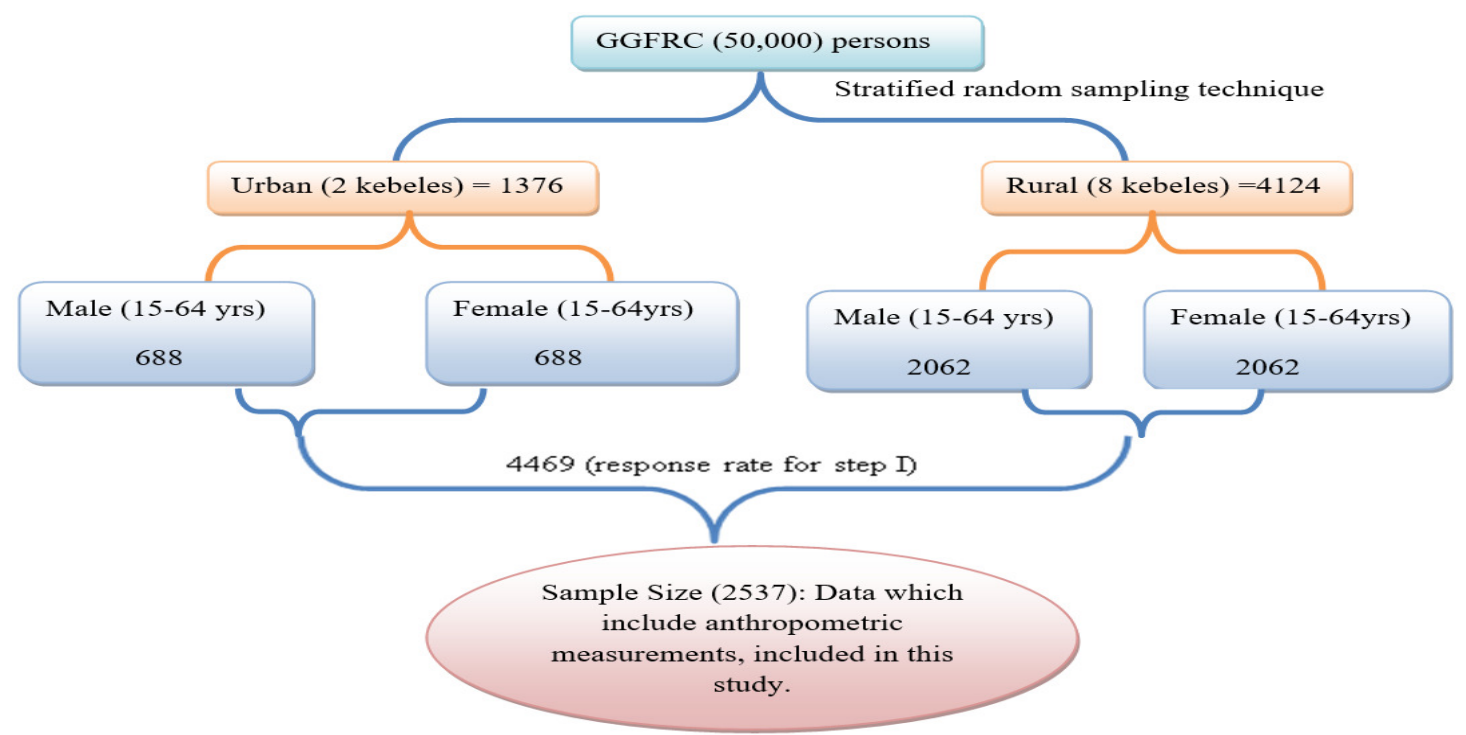

Figure:2 Schematic presentation of sampling procedure at GGFRC, Sept 2008 to Jan 2009

In the previous study, data collection instruments were adapted from WHO steps instruments [5]. The instruments were structured and contained questionnaire for step one and recording formats for step two and step three.The questionnaire for step one comprised questions about socio-demographic variables and behavioral risk factors for CNCDs including smoking cigarette, alcohol intake, fruit and vegetable intake, chat chewing, and physical activities. The recording formats were used to record physical measurement values of step two such as weight, height, waist and hip circumference, and values for biochemical tests of step three such as fasting blood sugar and total blood cholesterol level [3]. Fifteen interviewers, six physical measurement recorders and three supervisors who completed at least high school and competent in local languages were recruited and trained on how to obtain consent, use equipment and how to perform and record the physical measurements for data collection [3]. Face to face interview was conducted at home level and eligible respondents were declared unavailable if they were not found on three separate visits. After completion of face to face interview, all respondents were given appointment for physical measurements. Physical measurements were done after the interview for CNCDs survey and all respondents were given appointment to come to nearby health center, health post, at school and kebele offices for measurements. On the next morning physical measurements including weight, height, and waist and hip circumferences were measured following standard procedures. Additionally those respondents who were selected for biochemical tests were given instructions for overnight fasting (not to eat or drink after 8:00 pm) and early morning appointment given [6]. For this study the data were requested from GGFRC using a request form letter that includes a template which contains step one (socio-demographic and behavioural measurements), step two (anthropometric measurement) and step three (biochemical measurement) variables. Data extractor extracted the limited data set based on the requested data using template that includes list of variables, questions and specific objectives.

Data collection instruments were adapted from WHO steps instrument and translated into local languages (Amharic and Afan Oromo). Pre-test was conducted on the interview and measurement sections of the study instrument. After the pre-test investigators, supervisors and data collectors discussed on identified gaps. Standardized measuring instruments for anthropometric measurement were used. Daily supervision was made in the field during data collection by field supervisors and investigators. Data collectors and supervisors checked for data completeness and consistency on a daily basis [3].

Data were entered into the computer using EPI-Data version 3.1 and entered data were exported to SPSS Windows version 16.0 software [3]. Data were analyzed using SPSS. Univariate analysis was performed to see the distribution of variables. Data were checked for completeness, inconsistency, outliers and missing values by looking at their distribution. Incomplete, inconsistent and missing value were excluded from the analysis. Outcome variables were dichotomied as overweight and normal weight and also central obesity and no central obesity based on BMI and WHR indicator calculated from anthropometric measurement values (weight, height, waist and hip circumference). Bivariate analysis was run to see the association and strength of association between dependent and independent variables separately. Unadjusted odds ratios (COR) with $95 \%$ confidence interval for the bivariate analysis was presented and all variables with $p$-value less than 0.25 were considered as candidate variables for multivariate analysis. After multicollinarity (correlation matrix) and effect modifier/interaction (test of homogeneity of odds ratio) were checked for all candidate variables, multivariate logistic regression analysis was performed relating overweight and central obesity with selected characteristics. Adjusted odds ratios (AOR) with $95 \%$ confidence interval for multivariate analysis was reported and p-value of less than 0.05 was considered as a 
statistically significant. The results of the study were presented in tables and narrative form.

\section{Operational definitions}

The following operational definitions were used in this study.

Current tobacco user: currently smoke any tobacco products, such as cigarettes, cigars, or pipes $[5,7]$.

Alcohol use: consumed an alcoholic drink in the past 12 months [5, 8].

Daily smoker: currently smoke daily any tobacco products, such as cigarettes, cigars, or pipes [5].

Chat chewer: chewing chat in the lifetime.

Low fruits and vegetables intake (LFVI): defined as frequency of serving fruit and vegetable less than five per day [9].

Physical activity: the total time spent in physical activity during a typical week (total physical activity level); Inactive: inactive at work, transport and leisure time or less than 600 Metabolic Equivalent Task (MET)minutes/week; Medium: having a moderate activity or at least 600 MET-minutes per week and Vigorous: vigorous activity at work, transport or leisure time or at least 1,500 MET-minutes/weeks [10].

Overweight: define as body weight in kilograms divided by the square of the height in meters (BMI of $\geq 25 \mathrm{~kg}$ $\left./ \mathrm{m}^{2}\right)[3,5]$.

Central obesity: defined as waist to hip ratio (WHR) greater than one for men and greater than 0.85 for women $[5,7]$.

Fasting blood glucose level: defined as level of fasting blood glucose (in $\mathrm{mg} / \mathrm{dl}$ ) was separated into normal (< $110 \mathrm{mg} / \mathrm{dl}$ ) and elevated ( $\geq 110 \mathrm{mg} / \mathrm{dl})[7,8]$.

Total blood cholesterol: defined as high cholesterol as blood cholesterol level 5.22mmol/L or more [3].

\section{RESULTS}

Socio-demographic characteristics:- Out of the 2653 study participants who had data on anthropometric measurements, 2537 (95.6\%) were included in the study. The mean age of the study participants was 40.1 \pm 13.9 years and 563(22.2\%), 521(20.5\%), 550(21.7\%), 498(19.6\%) and 405(16.0\%) were 35-44, 45-54, 55-64, $25-34$ and 15-24 years of age respectively. One thousand three hundred and twenty seven $(52.3 \%)$ were female and $2168(85.5 \%)$ were rural residents. Two thousand and thirty eight $(80.3 \%)$ were uneducated while $499(19.7 \%)$ had at least attended primary school. One thousand two hundred and forty nine $(49.5 \%)$ were farmers and $868(65.4 \%)$ were housewife (table 1).

Table: 1 Study sample: socio-demographic characteristics at GGFRC, September 2008 - January 2009.

\begin{tabular}{lllll}
\hline \multirow{2}{*}{ Socio-demographic characteristics } & \multicolumn{2}{c}{ Sex } & \multicolumn{1}{c}{ Total } \\
\cline { 2 - 3 }$(\mathrm{N}(\%))$
\end{tabular}

Behavioural characteristics :- The study sample characteristics, on behavioural risk factors are presented in table 2. Nearly $21 \%$ and $70 \%$ of males were current smoker and chat chewer respectively. Ninety one percent $(91.1 \%)$ of current smokers were daily smokers and $65 \%$ of oil and fat used in the home was grain oil. 
Table: 2 Study sample: behavioural characteristics at GGFRC, September 2008 - January 2009.

\begin{tabular}{|c|c|c|c|c|}
\hline \multirow{2}{*}{ Behavioural characteristics } & & \multicolumn{2}{|c|}{ Sex } & \multirow{2}{*}{$\begin{array}{l}\text { Total } \\
(\mathrm{N}(\%))\end{array}$} \\
\hline & & Male (N (\%)) & Female $(\mathrm{N}(\%))$ & \\
\hline \multirow[t]{2}{*}{ Alcohol consumption } & No & $1128(93.5)$ & $1266(95.6)$ & $2394(94.6)$ \\
\hline & Yes & $79(6.5)$ & $58(4.4)$ & $137(5.4)$ \\
\hline \multirow[t]{2}{*}{ Chewing chat } & No & $366(30.2)$ & $1076(81.1)$ & $1442(56.8)$ \\
\hline & Yes & $844(69.8)$ & $251(18.9)$ & $1095(43.2)$ \\
\hline \multirow[t]{3}{*}{ Physical activity level } & Inactive & $290(24.7)$ & $364(29.4)$ & $654(27.1)$ \\
\hline & Moderate & $401(34.2)$ & $495(40.0)$ & $896(37.2)$ \\
\hline & Vigorous & $482(41.1)$ & $378(30.6)$ & $860(35.7)$ \\
\hline \multirow{2}{*}{$\begin{array}{l}\text { Number of serving } \\
\text { fruit and vegetables }\end{array}$} & $\geq 5$ serving & $872(72.1)$ & $918(69.2)$ & $1790(70.6)$ \\
\hline & $\overline{<} 5$ serving & $338(27.9)$ & $409(30.8)$ & $747(29.4)$ \\
\hline \multirow[t]{2}{*}{ Current smoker } & No & $959(79.3)$ & $1310(98.7)$ & $2269(89.4)$ \\
\hline & Yes & $251(20.7)$ & $17(1.3)$ & $268(10.6)$ \\
\hline \multirow[t]{2}{*}{ Daily smoker } & No & $20(8.4)$ & $3(16.7)$ & $23(8.9)$ \\
\hline & Yes & $245(91.6)$ & $15(83.3)$ & $245(91.1)$ \\
\hline \multirow[t]{5}{*}{ Use oil and fat } & Vegetable oil & $190(15.7)$ & $218(16.4)$ & $408(16.1)$ \\
\hline & Grain oil & $788(65.1)$ & $862(65.0)$ & $1650(65.0)$ \\
\hline & Butter & $24(2.0)$ & $20(1.5)$ & $44(1.7)$ \\
\hline & None in particular & $194(16.0)$ & $208(15.7)$ & $402(15.8)$ \\
\hline & None used & $14(1.2)$ & $19(1.4)$ & $33(1.3)$ \\
\hline \multirow{5}{*}{$\begin{array}{l}\text { Frequency of drinking } \\
\text { alcohol last } 12 \text { months }\end{array}$} & Daily & $9(11.4)$ & $2(3.4)$ & $11(8.0)$ \\
\hline & 5-6 days/wk & $9(11.4)$ & $9(15.5)$ & $18(13.1)$ \\
\hline & 1-4 days/wk & $26(32.9)$ & $13(22.4)$ & $39(28.5)$ \\
\hline & $\leq 3$ days/month & $35(44.3)$ & $34(58.6)$ & $69(28.5)$ \\
\hline & Total & 1210 & 1327 & 2537 \\
\hline
\end{tabular}

Factors associated with overweight and central obesity :- Different variables assumed to be associated with overweight and central obesity were included in the study. These include socio-demographic factors; behavioural characteristics and biological characteristics were included. The association of these factors with overweight and central obesity were seen using binary logistic regression.

On bivariate analysis, variables such as sex, educational status, occupational status, place of residence and chewing chat were found to have a statistically significant association with overweight at p-value less than 0.05 , but age, current smoker, daily smoker, fruit and vegetable consumption, physical activity, alcohol use, frequency of alcohol intake and use of oil and fat didn't show any association. Regarding central obesity, age, sex, educational status, occupational status, current smoker, chewing chat, fruit and vegetable consumption, use of oil and fat and physical activity were found to have a statistically significant association with central obesity at p-value less than 0.05. But place of residence, alcohol use, frequency of alcohol intake and daily smoker didn't show any significant association with central obesity on bivariate analysis (tables 3 and 4).

Socio-demographic characteristics of respondents :- Based on bivariate analysis done to show an association between socio-demographic characteristics with overweight and central obesity, female sex, being merchant, housewife and employee were found to have higher risk of overweight and central obesity. Those who attended education above nine grades, up to eight grades and urban resident were more likely to be overweight. On the other hand, respondents of age 25-34, 35-44, 45-54 and 55-64 years had higher risk of having central obesity. However, those who attended education up to grade four, up to grade eight and above grade nine had significantly lower risk of central obesity (table 3). 
Table: 3 Results of bivariate logistic regression analysis of overweight and central obesity with sociodemographic characteristics at GGFRC, September 2008 - January 2009.

\begin{tabular}{|c|c|c|c|c|c|}
\hline \multicolumn{2}{|c|}{ Socio-demographic characteristics } & \multicolumn{2}{|c|}{ Overweight } & \multicolumn{2}{|c|}{ Central obesity } \\
\hline & & $\mathrm{N}(\%)$ & $\operatorname{COR}(95 \% \mathrm{CI})$ & $\mathrm{N}(\%)$ & $\operatorname{COR}(95 \% \mathrm{CI})$ \\
\hline \multirow[t]{5}{*}{ Age in years } & $15-24$ & $4(1.0)$ & 1 & $116(28.6)$ & 1 \\
\hline & $25-34$ & $12(2.4)$ & $2.25(0.721-7.043) *$ & $185(37.1)$ & $1.57(1.17-2.10) * *$ \\
\hline & $35-44$ & $12(2.1)$ & $1.98(0.636-6.209) *$ & $215(38.2)$ & $1.64(1.23-2.18) * *$ \\
\hline & $45-54$ & $13(2.5)$ & $2.34(0.755-7.219) *$ & $205(39.3)$ & $1.72(1.29-2.29) * *$ \\
\hline & $55-64$ & $14(2.5)$ & $2.38(0.778-7.298) *$ & $228(41.5)$ & $1.88(1.41-2.49) * *$ \\
\hline \multirow[t]{2}{*}{ Sex } & Male & $16(1.3)$ & 1 & $79(6.5)$ & 1 \\
\hline & Female & $39(2.9)$ & $2.26(1.26-4.065) * *$ & $870(65.6)$ & $27(21.13-35.15) * *$ \\
\hline \multirow[t]{4}{*}{ Education } & Uneducated & $31(1.5)$ & 1 & $849(41.7)$ & 1 \\
\hline & 1-4 grade & $5(2.3)$ & $1.52(0.585-3.950)$ & $46(21.1)$ & $0.36(0.26-0.53) * *$ \\
\hline & $5-8$ grade & $7(3.8)$ & $2.6(1.120-5.930) * *$ & $37(20.2)$ & $0.36(0.24-0.52) * *$ \\
\hline & 9 or above & $12(12.2)$ & $9.03(4.48-18.20) * *$ & $17(17.3)$ & $0.29(0.17-0.49) * *$ \\
\hline \multirow[t]{7}{*}{ Occupation } & Farmer & $9(0.7)$ & 1 & $262(21.0)$ & 1 \\
\hline & Housewife & $24(2.7)$ & $3.8(1.75-8.160) * *$ & $591(65.7)$ & $7.21(5.94-8.74) * *$ \\
\hline & Employee & $9(16.1)$ & $26(10.0-69.51) * *$ & $8(14.3)$ & $0.63(0.29-1.344) *$ \\
\hline & Merchant & $10(12)$ & $18(7.44-47.88) * *$ & $27(32.5)$ & $1.82(1.13-2.93) * *$ \\
\hline & Daily laborer & $6(1.6)$ & $2.3(0.29-18.42)$ & $15(24.6)$ & $1.23(0.675-2.24) *$ \\
\hline & Student & $6(1.0)$ & $1.5(0.18-11.57)$ & $12(12.5)$ & $0.54(0.290-1.00) *$ \\
\hline & Unemployed & $6(1.2)$ & $1.7(0.218-13.9)$ & $28(35.0)$ & $2.03(0.856-3.28) *$ \\
\hline \multirow[t]{2}{*}{ Residence } & Rural & $25(1.2)$ & 1 & $806(37.2)$ & 1 \\
\hline & Urban & $30(8.1)$ & $7.58(4.40-13.06) * *$ & $143(38.8)$ & $1.07(0.852-1.341)$ \\
\hline
\end{tabular}

**P-value $<0.05, *$-value $<0.25 ; C O R$ - crude odds ratio; CI- confidence interval, $N(\%)$ - frequency and percentage of overweight and central obesity within socio-demographic variables.

Behavioural characteristics of respondents :- Physical inactivity, low fruit and vegetable consumption, use of butter and grain oil were found to have higher risk of having central obesity. On the other hand, chewing chat had lower risk of overweight and central obesity and current smoker had lower risk of central obesity (table 4).

Table: 4 Results of bivariate logistic regression analysis of overweight and central obesity with behavioural characteristics at GGFRC, September 2008 - January 2009.

\begin{tabular}{|c|c|c|c|c|c|}
\hline \multirow{2}{*}{\multicolumn{2}{|c|}{ Behavioural characteristics }} & \multicolumn{2}{|c|}{ Overweight } & \multicolumn{2}{|c|}{ Central obesity } \\
\hline & & \multirow{2}{*}{$\frac{\mathrm{N}(\%)}{49(2.0)}$} & \multirow{3}{*}{$\frac{\operatorname{COR}(95 \% \mathrm{CI})}{1}$} & \multirow{2}{*}{$\frac{\mathrm{N}(\%)}{905(37.7)}$} & \multirow{2}{*}{$\frac{\operatorname{COR}(95 \% \mathrm{CI})}{1}$} \\
\hline Alcohol use & No & & & & \\
\hline & Yes & $6(4.4)$ & & $44(32.1)$ & $0.78(0.54-1.13) *$ \\
\hline \multirow{4}{*}{$\begin{array}{l}\text { Frequency } \\
\text { alcohol use }\end{array}$} & Daily & & & $3(27.3)$ & $0.70(0.17-2.89)$ \\
\hline & 5-6 days/wk & & NA & $5(27.8)$ & $0.72(0.23-2.26)$ \\
\hline & 1-4 days/wk & & & $11(28.2)$ & $0.74(0.31-1.73)$ \\
\hline & $\leq 3$ days/month & & & $24(34.8)$ & 1 \\
\hline \multirow[t]{2}{*}{ Current smoker } & $\overline{N o}$ & $54(2.4)$ & 1 & $923(40.7)$ & 1 \\
\hline & Yes & $1(0.4)$ & $0.15(0.02-1.12) *$ & $26(9.7)$ & $0.2(0.12-0.24) * *$ \\
\hline \multirow[t]{2}{*}{ Daily smoker } & No & & NA & $5(20.8)$ & 1 \\
\hline & Yes & & & $21(8.6)$ & $0.36(0.12-1.05)$ \\
\hline \multirow[t]{2}{*}{ Chat chewing } & No & $39(2.7)$ & 1 & $731(50.7)$ & 1 \\
\hline & Yes & $16(1.5)$ & $0.5(0.29-0.96) * *$ & $218(19.9)$ & $0.24(0.2-0.29) * *$ \\
\hline Number of serving & $\geq 5$ servings/day & $44(2.5)$ & 1 & $640(35.8)$ & 1 \\
\hline fruit and vegetable & $<5$ servings/day & $11(1.5)$ & $0.59(0.31-1.12) *$ & $309(41.4)$ & $1.3(1.06-1.51) * *$ \\
\hline \multirow[t]{5}{*}{ Use of oil and fat } & Vegetable oil & $9(2.2)$ & 1 & $125(30.6)$ & 1 \\
\hline & Grain oil & $30(18.2)$ & $0.82(0.39-1.74)$ & $625(37.9)$ & $1.4(1.09-1.74) * *$ \\
\hline & Butter & $2(4.5)$ & $2.1(0.44-10.09)$ & $21(47.7)$ & $2.1(1.10-3.87) * *$ \\
\hline & None in particular & $13(3.2)$ & $1.48(0.63-3.51)$ & $164(40.8)$ & $1.6(1.17-2.08) * *$ \\
\hline & None used & $1(3.0)$ & $1.39(0.17-11.3)$ & $14(42.4)$ & $1.67(0.81-3.43)$ \\
\hline \multirow{3}{*}{$\begin{array}{l}\text { Physical activity } \\
\text { level }\end{array}$} & Inactive & $12(1.8)$ & $0.79(0.38-1.62)$ & $277(42.4)$ & $1.6(1.29-1.98)^{* * *}$ \\
\hline & Moderate & $21(2.3)$ & $1.01(0.54-1.87)$ & $335(37.4)$ & $1.3(1.07-1.59) * *$ \\
\hline & Vigorous & $20(2.3)$ & 1 & $270(31.4)$ & 1 \\
\hline
\end{tabular}

**p-value $<0.05, * p$-value $<0.25, N A-$ Not applicable due to sample inadequacy in cells; $N(\%)$ - frequency and percentage of overweight and central obesity within behavioral characteristics; COR- crude odds ratio; CIconfidence interval. 
Biological characteristics of respondents :- Biological characteristics such as fasting blood glucose, diabetes mellitus and total blood cholesterol didn't show any significant association with overweight and central obesity on bivariate analysis (table 5).

Table: 5 Results of bivariate logistic regression analysis of overweight and central obesity with biological characteristics at GGFRC, September 2008 - January 2009.

\begin{tabular}{lllllc}
\hline \multirow{2}{*}{ Biological characteristics } & \multicolumn{2}{c}{ Overweight } & \multicolumn{2}{c}{ Central obesity } \\
\cline { 2 - 5 } & \multicolumn{1}{l}{$\mathrm{N}(\%)$} & $\mathrm{COR}(95 \% \mathrm{CI})$ & $\mathrm{N}(\%)$ & $\mathrm{COR}(95 \% \mathrm{CI})$ \\
\hline Fasting blood & $<110 \mathrm{mg} / \mathrm{dl}$ & $19(1.5)$ & 1 & $471(37.8)$ & 1 \\
sugar & $\geq 110 \mathrm{mg} / \mathrm{dl}$ & $6(3.1)$ & $2.05(0.808-5.195)$ & $75(38.5)$ & $1.03(0.753-1.405)$ \\
Diabetes & No & $54(2.1)$ & 1 & $939(37.3)$ & 1 \\
& Yes & $1(4.8)$ & $2.28(0.300-17.29)$ & $10(47.6)$ & $1.03(0.808-1.352)$ \\
Total & $<5.22 \mathrm{mmol} / \mathrm{L}$ & $2(0.7)$ & 1 & $114(37.5)$ & 1 \\
cholesterol & $\geq 5.22 \mathrm{mmol} / \mathrm{L}$ & $24(1.6)$ & $2.51(0.591-10.69)$ & $564(38.5)$ & $1.53(0.652-3.341)$ \\
\hline
\end{tabular}

$N(\%)$ - frequency and percentage of overweight and central obesity within biological characteristics; CIconfidence interval.

Sex, age, educational status, occupational status, place of residence, alcohol use, current smoker, chewing chat and fruit and vegetable consumption were selected for multivariate analysis, for overweight. As well as sex, age, educational status, occupational status, current smoker, alcohol use, fruit and vegetable consumption, physical activity, chewing chat and use of oil and fat were candidates for multivariate analysis for central obesity. Before including variables in the multivariate analysis, multicollinarity and interaction or effect modifier were checked for all variables candidate for multivariate analysis. As a result, multicollinarity and interaction or effect modifier were not found. Proceeding, checked of multicollinarity and interaction or effect modifier, multivariate analysis was then run to identify independently associated variables with overweight and central obesity.

Factors independently associated with overweight and central obesity :- In multivariate logistic regression analysis, evaluating the association of selected characteristics with overweight and central obesity results are shown in table 6. Accordingly, older age, female sex, urban resident, being merchant, employee and higher educational status were found to be independently associated with overweight [hosmer and lemeshow test for the model fitness, $\left.x^{2}=3.72, \mathrm{df}=8, \mathrm{p}=0.882\right]$. Moreover, Females had three times higher risk of having overweight as compared to male $(\mathrm{AOR}=3.1 ; 95 \% \mathrm{CI}, 1.37-6.98)$, adjusting for other socio-demographic characteristics. The risk of overweight was four times higher in urban residents and six times higher in higher educational status as compared to counterparts $(\mathrm{AOR}=4.2 ; 95 \% \mathrm{CI}, 2.170-8.180)$ and $(\mathrm{AOR}=6.2 ; 95 \% \mathrm{CI}, 2.120-17.95)$, respectively, adjusting for other factors including sex and age.

On the other hand, respondents of age 25-34, 45-54 and 55-64 years had nearly four, five and eight times more likely to have overweight as compared to youngest age (AOR=3.8; 95\%CI, 1.021-14.50), (AOR=5.0; $95 \% \mathrm{CI}, 1.280-19.36)$ and $(\mathrm{AOR}=8.3 ; 95 \% \mathrm{CI}, 2.080-33.20)$, respectively, adjusting for other factors including sex and place of residence. Employee and merchant had nearly six and five times higher risk of having overweight as compared to farmers $(\mathrm{AOR}=5.9 ; 95 \% \mathrm{CI}, 1.660-21.03)$ and $(\mathrm{AOR}=5.0 ; 95 \% \mathrm{CI}, 1.650-14.82)$, respectively, adjusting for other socio-demographic characteristics. But, current smoker, alcohol use, low fruit and vegetable consumption were not associated with overweight (table 6).

Regarding central obesity, older age, female sex, higher educational status, student, current smoker, chewing chat and use of butter and grain oil were found to be independent associated with central obesity [hosmer and lemeshow test for the model fitness, $x^{2}=8.37, \mathrm{df}=8, \mathrm{p}=0.398$ ]. Furthermore, the risk of central obesity was about three times higher in subjects aged 55-64 years $(\mathrm{AOR}=2.5 ; 95 \% \mathrm{CI}, 1.713-3.671)$, two times higher in subjects age 45-54 years $(\mathrm{AOR}=2.12 ; 95 \% \mathrm{CI},(1.451-3.060)$, about two times higher risk in subjects aged 35-44 years $(\mathrm{AOR}=1.73 ; 95 \% \mathrm{CI}, 1.210-2.460)$ and subjects age $25-34$ years had a $63 \%$ increased $(\mathrm{AOR}=1.6 ; 95 \% \mathrm{CI}, 1.120$ 2.290) compared to the youngest subjects, adjusting for other socio-demographic factors. Females had twelve times higher risk of having central obesity as compared to male ( $\mathrm{AOR}=12 ; 95 \% \mathrm{CI}, 4.27-20.46)$, adjusting for other factors including age and place of residence. Student, current smoker, chat chewer and higher educational status had $59 \%, 86 \%, 56 \%$ and $64 \%$ lower risk of central obesity than their counterparts (AOR $=0.41 ; 95 \% \mathrm{CI}$, $0.184-0.930),(\mathrm{AOR}=0.14 ; 95 \% \mathrm{CI}, 0.095-0.219),(\mathrm{AOR}=0.44 ; 95 \% \mathrm{CI}, 0.359-0.545)$ and $(\mathrm{AOR}=0.36 ; 95 \% \mathrm{CI}$, 0.213-0.736), respectively, adjusting for other factors. On the other hand, the use of butter as oil in the home was about five times higher risk of developing central obesity as compared to the use of vegetable oil (AOR=4.84; $95 \% \mathrm{CI}, 1.920-12.184)$. However, alcohol use, physical inactivity, low fruit and vegetable consumption were not associated with central obesity (table 6). 
Table: 6 Multivariate logistic regression analysis relating overweight and central obesity with selected characteristics at GGFRC, September 2008 - January 2009.

\begin{tabular}{|c|c|c|c|c|c|}
\hline \multirow{2}{*}{ Independent variables } & & \multicolumn{2}{|r|}{ Overweight } & \multicolumn{2}{|c|}{ Central obesity } \\
\hline & & $\%$ & $\operatorname{AOR}(95 \% \mathrm{CI})$ & $\%$ & $\mathrm{AOR}(95 \% \mathrm{CI})$ \\
\hline \multirow[t]{5}{*}{ Age in years } & $15-24$ & 1.0 & 1 & 28.6 & 1 \\
\hline & $25-34$ & 2.4 & $3.8(1.021-14.50) *$ & 37.1 & $1.60(1.12-2.290)^{*}$ \\
\hline & $35-44$ & 2.1 & $3.6(0.930-13.94)$ & 38.2 & $1.73(1.21-2.460) * *$ \\
\hline & $45-54$ & 2.5 & $5.0(1.280-19.36)^{*}$ & 39.3 & $2.12(1.45-3.060) * * *$ \\
\hline & $55-64$ & 2.5 & $8.3(2.080-33.20) * *$ & 41.5 & $2.51(1.71-3.670) * * *$ \\
\hline \multirow[t]{2}{*}{ Sex } & Male & 1.3 & 1 & 6.5 & 1 \\
\hline & Female & 2.9 & $3.1(1.37-6.98) * *$ & 65.6 & $12(4.27-20.46) * * *$ \\
\hline \multirow[t]{4}{*}{ Education } & Uneducated & 1.5 & 1 & 41.7 & 1 \\
\hline & 1-4 grade & 2.3 & $1.95(0.670-5.672)$ & 21.1 & $1.04(0.660-1.630)$ \\
\hline & $5-8$ grade & 3.8 & $2.22(0.807-6.090)$ & 20.2 & $0.58(0.360-0.940) *$ \\
\hline & 9 or above & 12.2 & $6.2(2.120-17.95) * *$ & 17.3 & $0.36(0.210-0.736) * *$ \\
\hline \multirow[t]{7}{*}{ Occupation } & Farmer & 0.7 & 1 & 21 & 1 \\
\hline & Employee & 16.1 & $5.9(1.660-21.03) * *$ & 14.3 & $0.85(0.308-2.370)$ \\
\hline & Merchant & 12.0 & $5.0(1.650-14.82) * *$ & 32.5 & $0.85(0.443-1.648)$ \\
\hline & Daily laborer & 1.6 & $0.45(0.050-4.120)$ & 24.6 & $1.18(0.511-2.706)$ \\
\hline & Student & 1.0 & $1.60(0.140-17.70)$ & 12.5 & $0.41(0.184-0.930) *$ \\
\hline & Housewife & 2.7 & $1.49(0.590-3.770)$ & 65.7 & $1.12(0.858-1.508)$ \\
\hline & Unemployed & 1.2 & $0.43(0.050-3.920)$ & 35 & $0.78(0.393-1.566)$ \\
\hline \multirow[t]{2}{*}{ Residence } & Rural & 8.1 & 1 & & \\
\hline & Urban & 1.2 & $4.2(2.170-8.180) * * *$ & & NI \\
\hline \multirow[t]{2}{*}{ Current smoker } & No & 2.4 & 1 & 40.7 & 1 \\
\hline & Yes & 0.4 & $0.38(0.050-2.990)$ & 9.7 & $0.14(0.095-0.219) * * *$ \\
\hline \multirow[t]{2}{*}{ Chewing chat } & No & 2.7 & 1 & 50.7 & 1 \\
\hline & Yes & 1.5 & $1.09(0.541-2.180)$ & 19.9 & $0.44(0.359-0.545) * *$ \\
\hline Number of serving & $\geq 5$ serving/day & 2.5 & 1 & 35.8 & 1 \\
\hline fruit and vegetable & $\overline{<5}$ serving/day & 1.5 & $0.50(0.250-1.040)$ & 41.4 & $1.15(0.902-1.470)$ \\
\hline Physical activity & Inactive & & & 42.4 & $1.105(0.827-1.477)$ \\
\hline \multirow[t]{2}{*}{ Level } & Moderate & & NI & 37.4 & $0.92(0.706-1.193)$ \\
\hline & Vigorous & & & 31.4 & 1 \\
\hline \multirow[t]{5}{*}{ Use of oil and fat } & Vegetable oil & & & 30.6 & 1 \\
\hline & Grain oil & & & 37.9 & $1.75(1.23-2.340) * * *$ \\
\hline & Butter & & NI & 47.7 & $4.8(1.920-12.18) * * *$ \\
\hline & $\begin{array}{l}\text { None } \\
\text { particular }\end{array}$ & & & 40.8 & $2.14(1.46-3.140) * * *$ \\
\hline & None used & & & 42.4 & $1.73(0.616-4.84)$ \\
\hline \multirow[t]{2}{*}{ Alcohol use } & No & 2.0 & 1 & 37.7 & 1 \\
\hline & Yes & 4.4 & $0.82(0.310-2.160)$ & 32.1 & $1.17(0.703-1.944)$ \\
\hline
\end{tabular}

\section{DISCUSSION}

This study revealed two major findings. Firstly, in the study population increasing age, female sex, higher educational status, urban residence, being merchant and employee were significantly associated with overweight. Secondly, increasing age, female sex, higher educational status, being student, current smoker, chewing chat and use of butter and grain oil were significantly associated with central obesity.

Older age was positively associated with overweight as compared to youngest age in this study. This is in line with the studies done in a Kerale state of India and ICMR [11, 12]. The explanation could be the youngest age group may be more conscious of their body image such that they may take healthy diet or exercise physical activity to control their weight. Regarding central obesity, increasing age was found to be associated with an increased risk for central obesity. This is similar to findings from the study done in Kerala state of India, ICMR, Zambia and Tanzania $[11,12,13,14]$. The explanation could be the youngest age group may be more conscious of their body image such that they may take healthy diet or exercise physical activity and also due to the fact that as age increase physical activities decrease.

Female sex was significantly associated with an increased risk for overweight and central obesity as compared to male in this study. This is similar to findings from the study done in Kerala in India, ICMR, South Africa and 
Addis Abeba $[11,12,15,16]$. This observation could be due to that females are more exposed to the effects of excess adiposity and also due the use of a lower threshold for central obesity in females [17].

Urban residence was positively associated with overweight in the current study. This finding is similar with the finding from the study done in India and ICMR [11,12]. This indicates that rural residents are involved in agricultural activities and also higher risk of overweight among urban residents could be explained due to epidemiological transition that results from urbanization [18]. Employee (government and non-government) and merchant were associated with an increased risk for overweight. This is inconsistent with finding from the studies done in Kerala in India and South Africa [11,16]. This could be due to the difference in occupational status categorization, in which the farmers were included in this study.

Higher educational status was associated with an increased risk for overweight in the current study. This is observed in the study done in India and Zambia [11,13]. This may be due to lifestyle difference, in which there is an epidemiological transition of lifestyle and urbanization [18]. According to this finding, higher educational status was found to be negatively associated with central obesity. This is similar to findings from the study done in India and Zambia [11, 13]. The explanation could be respondents of higher educational attainment is associated with increased knowledge that in turn enables an individual to make healthy choices.

The use of butter and grain oil were significantly associated with central obesity as compared to vegetable oil in the present study. The explanation could be high intake of high energy foods or fats such as butter and grain oil promote central obesity compared to low energy foods such as vegetables oil. In this study, the tobacco use was negatively associated with central obesity. This is in line with the findings from the study done in Kerala state of India, ICMR of India and Zambia $[11,12,13]$. The explanation for this finding could be tobacco use has an effect on gastrointestinal of the metabolic system, responsible for digestion of food and absorption of nutrients [19]. But, tobacco use was not associated with overweight which is inconsistent with the above studies and alcohol use was not associated with overweight and central obesity. This is inconsistent with findings from the study done in India and ICMR $[11,12]$. The reason could be due to the population distribution is not various in religion, in which the muslim followers are dominant in the study area and determines alcohol use.

Chewing chat was negatively associated with central obesity in the present study. This is inconsistent with findings from the study done in JUSH [20]. The observed finding, indicates that chat has an effect on gastrointestinal system that decrease food consumption, decreased absorption of food and induced anorexia and constipation [21]. The inconsistency could be due to the difference in study characteristics, in which this study is in a community setting and the comparative one is an institutional based study.

Physical inactivity was not associated with overweight and central obesity in the current study. This is inconsistent with studies done in India, ICMR and Tanzania $[11,12,16]$. This might be explained by a higher physical activity rate in rural resident adults involved in this study, in which about $85 \%$ study subjects included in this study are from rural residents.

Elevated fasting blood glucose was not associated with overweight and central obesity in this study. This is inconsistent with the study done in ICMR [12]. This may be due to fasting blood sugar was not measured from all study participants included in this study particularly for individuals who had overweight and central obesity. The stratified sampling procedure undertaken to select the study subjects considered the sample representative of a minority group and data collection instruments were adapted from the WHO stepwise approach manual included in the study is considered as strength of the study. And also this study had a few limitations: Data were collected cross sectional, in which cross-sectional nature of the data limits temporality and causality interpretation. Therefore, we cannot describe causation on the relations of the variables found associated with the outcome measure (overweight and central obesity). Secondary analysis of data is restricted by original study or data, in which information on marital status and familial obesity were not available and this finding might have been biased if marital status and familiar obesity were a confounding factor. There might have been an interobserver variation during anthropometric measurements. Although the research team followed the WHO steps Guideline, it is impossible to avoid the interobserver variation in the measurements. Social desirability bias may be present on substance use due to the respondents would like to have acceptance of persons. Lastly, the social distribution of our study population of the smaller towns Assendabo, Deneba and Dimtu included in this study cannot be taken to represent the urban population in its strict sense and the majority of our study population were subsistence farmers who involved in more strenuous activities compared with urban population. For this reason, the association of physical inactivity with overweight and central obesity might have been biased.

\section{CONCLUSION AND RECOMMENDATION}

On the basis of the information collected from the 2537 individuals; this study has come up with the following plausible conclusion. Socio-demographic characteristics, older age and female sex were positively independent predictors of overweight and central obesity. In addition higher educational status, employee and merchant occupational status and urban residence were positively independent predictors for overweight. But higher educational status and being student were negatively associated with central obesity. Use of butter and grain oil 
was positively associated with central obesity. But being current smoker and chat chewer were negatively associated with central obesity. These findings are crucial for evidence based decision making and it will help policy makers for planning of preventive and control measures of these risk factors. Based on this finding,to reduce the burden of overweight and central obesity in the community we recommend. Oromia Regional Health Bureau should encourage health facilities to promote prevention and control of overweight and central obesity among females, urban residents, members with higher educated persons, merchants, government and non-government employee. All Health facilities should also encourage health professionals and urban health extension professionals to promote healthy life style in the community. Females should improve their lifestyle through increased physical activities and improved dietary intake. This could be through increasing their physical activities, for instance by walking or jogging. Highly educated persons, employee and merchants should control their body weight regularly to prevent themeselves from being overweight. Urban residents should improve their lifestyle by preventing urbanization lifestyle. This could be through walking rather than use of transport and preventing from a long time of watching TV or use of computer. People who are currently chewing chat and use tobacco should stop chewing and smoking. Finally Researchers should conduct further and similar studies aimed on assessing the overweight and central obesity in the community setting.

\section{Competing interests}

The authors declare that they have no competing interests.

\section{Authors' contributions}

Girma Yazew is participated in conceptualized the study, designed the study instrument and conducted the data analysis.

Abdulkerim Abate, Fessahaye Alemseged and Tsegaye Tewelde ${ }^{4}$ are participated in approved the research proposal with some revisions, participated in data analysis, prepare manuscript, revised subsequent drafts of the paper and involve in critical review of the manuscript. All authors read and approved the final manuscript.

\section{Acknowledgement}

We owe great gratitude to the Gilgel Gibe Field Research Center of Jimma University; and College of Public Health and Medical Science of Jimma University, Department of Epidemiology for facilitating the study to be conducted. Finally we thanks all data collectors.

\section{REFERENCES}

1. WHO. Public Health Agency of Canada on preventing chronic diseases. Geneva: WHO; 2005. [http://www.who.int/chp/chronic_disease_report/full_report] (Accessed 12 November 2012).

2. Finucane MM. National, regional, and global trends in body-mass index since 1980: systematic analysis of health examination surveys and epidemiological studies with 960 country-years and 9.1 million participants. The Lancet. 2011; 337(9765):557-567.

3. Alemseged F., Woldemichael K., Asefa M., Tessema F., H/Amlak A., Tegegn A. et al. Risk factors for chronic non-communicable diseases. Ethiopian Journal of Health Sciences. 2012; 22 (special issue): 29-37.

4. Méjean C., Traissac P., Eymard-Duvernay S., Ati JE., Delpeuch F and Maire B. Influence of socio-economic and lifestyle factors on overweight and nutrition-related diseases among Tunisian migrants versus nonmigrant Tunisians and French. BMC Public Health. 2007; 7:265 doi: 10.1186/1471-2458-7-265. https://doi.org/10.1186/1471-2458-7-265

5. WHO. Chronic diseases and health promotion: Stepwise approach to surveillance (STEPS). Geneva: WHO; 2008.

[http://whqlibdoc.who.int/publications] (Accessed 12 Octomber 2012).

6. EJHS. Chronic illness survey and Biological profile for evidence based practices in Medicine and Public Health: The Gilgel Gibe Field Research Center Experience, Southwest Ethiopia. Jimma University: Research and Publications Office. August 2012; 22 (Special issues):7-61.

7. Chongsuvivatwong V., YipIntsoi T., Apakupakul N. Gender and ethnic differences in cardiovascular risks in Songkhla province, Thailand: the interASIA-south. J Med Assoc Thai. 2008; 91: 464-70.

8. Chongsuvivatwong V., Yipintsoi T., Suriyawongpaisal P., Cheepudomwit S., Aekplakorn W., Faramnuayphol P. et al. Comparison of Cardiovascular Risk Factors in Five Regions of Thailand: InterASIA Data. J Med Assoc Thai. 2010; 93 (1): 17-26. (8)

9. Department of Agriculture. Dietary guidelines for Americans 2005. Washington, DC, US Government Printing Office. 2006. [www.healthierus.gov/dietaryguidelines] (accessed on January 2, 2013).

10. WHO. Global physical activity questionnaire analysis guide. Geneva: WHO; 2011. [http://whqlibdoc.who.int/publications/2010/9789241599979_eng.pdf] (Accessed November 26, 2012).

11. Sugathan TN., Soman CR and Sankaranarayanan K. Behavioural risk factors for non-communicable diseases 
among adults in Kerala, India. Indian Journal of Medical Research. 2008; 127: 555-563.

12. Thankappan KR., Shah B., Mathur P., Sarma PS., Srinivas G., Mini GK., et.al. Risk factor profile for chronic non-communicable diseases: Results of a community-based study in Kerala, India. Indian Journal Medical Research. 2010; 131: 53-63.

13. Rudatsikira E., Muula AS., Mulenga D. and Siziya S. Prevalence and correlates of obesity among Lusaka residents, Zambia: a population-based survey. International Archives of Medicine. 2012; 5:14. doi: $10.1186 / 1755-7682-5-14$

14. Shayo GA. and Mugusi FM. Prevalence of obesity and associated risk factors among adults in Kinondoni municipal district,Dar es Salaam Tanzania. BMC Public Health. 2011; 11:365. https://doi.org/10.1186/14712458-11-365

15. Tesfaye F., Byass P. and Wall S. Population based prevalence of high blood pressure among adults in Addis Ababa: uncovering a silent epidemic. BMC Cardiovascular Disorders. 2009; 9:39. https://doi.org/10.1186/1471-2261-9-39

16. Malhotra R., Hoyo C and Hughes G. Determinants of obesity in an urban township of South Africa. South Africa Journal Clinical Nutrition. 2008; 21(4):315-320. (16)

17. George AB and Claude B. Handbook of Obesity: Evaluation and Treatment. Third edition. USA. Newyork. Third edition. 2008:29

18. WHO. Preventing chronic diseases: a vital investment. WHO global health report. Geneva: WHO, 2005.

19. Doe J. and Santo DE. Smoking's immediate effects on the body. Campaign for Tobacco-Free Kids. September 17, 2009. [http://www.tobaccofreekids.org/facts_issues/fact_sheets/toll/products/] (Accessed May 26, 2013)

20. Tamiru S. and Alemseged F. Risk factors for cardiovascular diseases among diabetic patients in South West Ethiopia. Ethiopia Journal of Health Science. 2010; 20(2):121-128.

21. Islam MW, al Shabanah OA, al Harbi MM, al Gharably NM. Evaluation of teratogenic potential of khat (Catha edulis Forsk.). Drug Chem Toxicol 1994;17:51-68. DOI:10.3109/01480549409064046 